\section{Assessment of driver vision functions in relation to their crash involvement in India}

\author{
Ashish Verma ${ }^{1,5, *}$, Neelima Chakrabarty ${ }^{2}$, \\ S. Velmurugan ${ }^{2}$, B. Prithvi Bhat ${ }^{3}$, \\ H. D. Dinesh Kumar ${ }^{1}$ and B. Nishanthi ${ }^{4}$
}

${ }^{1}$ Department of Civil Engineering and ${ }^{5}$ Centre for Infrastructure, Sustainable Transportation and Urban Planning,

Indian Institute of Science, Bengaluru 560 012, India

${ }^{2}$ Traffic Engineering and Safety Division, Central Road Research

Institute, Mathura Road, New Delhi 110 025, India

${ }^{3}$ Central Institute of Road Transport, Pune 411 026, India

${ }^{4}$ Department of Civil Engineering, National Institute of Technology,

Tiruchirappalli 620015 , India

Among the human factors that influence safe driving, visual skills of the driver can be considered fundamental. This study mainly focuses on investigating the effect of visual functions of drivers in India on their road crash involvement. Experiments were conducted to assess vision functions of Indian licensed drivers belonging to various organizations, age groups and driving experience. The test results were further related to the crash involvement histories of drivers through statistical tools. A generalized linear model was developed to ascertain the influence of these traits on propensity of crash involvement. Among the sampled drivers, colour vision, vertical field of vision, depth perception, contrast sensitivity, acuity and phoria were found to influence their crash involvement rates. In India, there are no efficient standards and testing methods to assess the visual capabilities of drivers during their licensing process and this study highlights the need for the same.

Keywords: Crash involvement, driver licensing, generalized linear modelling, visual functions.

DRIVING typically forms the primary and preferred approach of travel in many countries around the world ${ }^{1}$, the ill consequences of which are road crashes. According to the report by the Ministry of Road Transport and Highways, Government of India ${ }^{2}$, driver fault forms a significant share of the causes of road accident in India. Figure 1 shows the causal factors of road accidents in India in 2013, along with the percentage share.

Human functional failure can be assessed by identifying the limits in human functions that allow a person to adapt to changing situations, for example, experience, visual abilities, risk taking behaviour, etc. With respect to driving, human functional failures can arise from endogenous (inabilities of drivers) and/or exogenous factors (environment which influences endogenous factors) ${ }^{3}$.
Human functional failures along with their defective interactions with factors such as human, vehicle and environment are the key reasons for road accidents.

Human functions with respect to driving primarily include perceptual and/or cognitive performance such as visual performance, auditory skills, bio-mechanical skills, speed judgment and adaption, reaction time, attention, etc. $^{4-6}$. They can be broadly classified into two categories-physical and psychological. The present work focuses on identifying the relation between visual functions and crash involvement propensity of drivers in India.

Physical functions of drivers are important parameters in evaluating their safe driving abilities ${ }^{7}$. Vision skills are among the prominent physical functions that assist a driver in perceiving traffic situations. These functions are difficult to quantify and to consider them in road safety evaluation is a difficult task. In heterogeneous and complex traffic conditions commonly witnessed in India, drivers need to remain vigilant throughout, to safely respond to vehicles of different sizes coming their way abruptly from any direction. The complexities further magnify while driving heavy-vehicles. This has caused an increasing number of heavy-vehicle crashes in many Indian cities ${ }^{8,9}$. Assessing the influence of visual abilities on crash involvement is essential in identifying the underlying causes of accidents due to driver fault.

A simple, multi-disciplinary test comprising of assessment of vision and cognitive tests, hazard perception and change detection tests was found to have a significant capacity to evaluate how safe or unsafe a driver is ${ }^{10}$. To assess visual fitness of a driver, visual acuity, contrast sensitivity and peripheral vision form critical components ${ }^{11}$. Impairment in visual skills was found to be a significant causal factor for road crashes in drivers above the age of 70 years $^{12}$.

Several studies have been conducted worldwide to investigate the influence of visual skills on crash propensity.

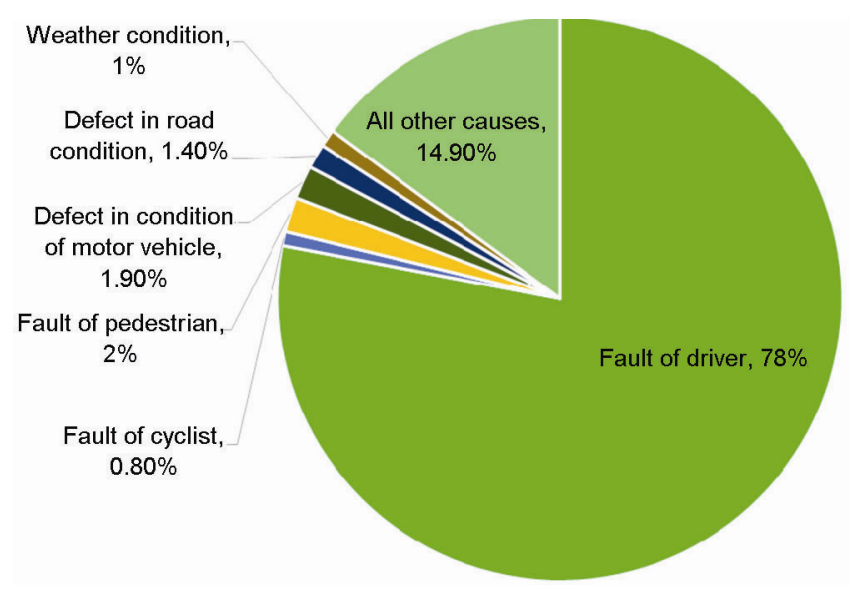

Figure 1. Causes of road accidents in India (2013). 
Drivers with binocular visual acuity are found to have a higher crash risk compared to those with normal vision. In an experiment conducted by Hofstetter ${ }^{13}$, persons with binocular visual acuity problems reported double the accident risks compared to those with normal vision. Estimation of effect of binocular vision on road crash distributions of taxi drivers revealed that the average crashes per year were more in drivers with problems in binocular vision ${ }^{14}$. Recent research also supports the association of visual impairment and motor vehicle crashes, specifically in older drivers ${ }^{12}$.

Depth perception plays an essential role in judging the speed of oncoming vehicles while driving. Inabilities in speed judgment may contribute to crash risks ${ }^{15}$. Researchers also believe that colour vision and glare recovery strongly associate with poor driving performances $^{16,17}$. Protanopia, defined as red-green colour blindness, is considered critical in the Australian driver licensing procedure. Since 1994, any person with protanopia is restricted from getting commercial driving licence in Australia. Studies reveal that regardless of severity, protanopia highly influences the risk of road accidents $^{18}$.

Since many roads in India are undivided, overtaking vehicles often come in conflict with oncoming vehicles from the opposite end. In a road accident investigation study conducted on national highways, it was observed that all the nine head-on collisions observed on undivided highways were mainly due to overtaking vehicles entering into the oncoming vehicle lane ${ }^{19}$. Tendency of not maintaining safe stopping sight distance is also a drawback among many Indian drivers, leading to risky situations on Indian roads. In such cases satisfactory depth perception becomes important in ensuring the safety of drivers.

Glare can be defined as the sensation caused when bright light is flashed in front of one's eyes, obstructing his/her vision for a couple of seconds. This is a common phenomenon witnessed in night-time driving due to the use of high beam lights. Time taken to recovery from this glare varies in individuals depending on their age and vision conditions. Glare increases reaction time in drivers, thereby influencing their safety in a negative manner ${ }^{20,21}$. Again, due to the presence of many undivided roads in India, acceptable glare recovery is important to avoid collisions.

In simple terms, contrast sensitivity can be defined as the ability to distinguish between an object from its background. Studies have shown that persons with contrast sensitivity impairment restrict themselves from driving, thereby reducing their annual mileage. This self-regulation is mainly seen due to the increased risk of motor vehicle collisions $^{22}$. Also, depth perception of on-coming vehicles is affected by contrast sensitivity ${ }^{23-25}$. Influence of phoria on driving performance was ascertained in the studies conducted by Burg ${ }^{26}$.
Performance of drivers with central field of vision impairment and normal peripheral vision was evaluated by Lamble et al. ${ }^{27}$. It was observed that the reaction time of these drivers was higher compared to those with normal vision. Also, persons with central vision loss had a greater likelihood of involving in night-time crashes $^{28}$. Drivers with binocular visual field loss were found to have a higher crash and conviction risk compared to those with normal vision ${ }^{29}$.

Table 1 summarizes the significance of each of the above-mentioned vision parameters in relation to driving.

Vision test is an essential component of commercial driver licensing in the United States. All states in the US have visual acuity requirements for licensure, and all but three have set the minimum 'best corrected visual acuity' (BCVA) requirement at 20/40 in the better eye. Georgia requires a $\mathrm{BCVA}$ of at least 20/60 in at least one eye; for New Jersey and Wyoming, the requirement is 20/50. For the 34 states with a binocular horizontal visual field requirement, 15 stipulate $140^{\circ}$; for the other 19 states, the range is from $105^{\circ}$ to $130^{\circ}$; Maine requires $150^{\circ}$. Several states list the horizontal dimension of the visual field of applicants with only one useful eye; this ranges from $55^{\circ}$ (Kansas) to $105^{\circ}$ (Arkansas). Some states, including North Carolina and Texas, do not issue any driver's licence to a person with homonymous hemianopia (loss of vision in the right half or left half of both eyes). Only Kentucky has a vertical visual field requirement: $25^{\circ}$ above and below the fixation point ${ }^{30}$.

In the United Kingdom, separate vision test standards are followed for private driver licence and commercial driving licence (for bus and lorry drivers) applicants. For private driver licence, a minimum visual acuity of $6 / 12$ for both eyes, as measured in Snellen's chart is required. Also, adequate field of vision that is attested by an ophthalmologist is essential. For bus and lorry drivers, visual acuity of 6/7.5 at least in the best eye and 6/60 in the other is mandated. Horizontal field of vision of $106^{\circ}$, with extensions not less than $70^{\circ}$ towards left and right and $30^{\circ}$ above and below, with no defects in the central field of $30^{\circ}$ is also a must ${ }^{31}$.

Australia also follows separate vision requirements for private diver licence and commercial driving licence. A minimum of $6 / 12$ visual acuity in the better eye or both eyes is essential to avail unconditional private driving licence. Conditional licence is considered for applicants who meet these standards with corrective lenses. For commercial driving licence, a minimum visual acuity of $6 / 9$ in the better eye and $6 / 18$ in the worse eye is required. For applicants with visual acuity worse than $6 / 24$, driver licence is rejected. Horizontal field of vision extending up to $110^{\circ}$ and $10^{\circ}$ respectively, above and below the horizontal midline is mandatory for private driver licence, whereas for commercial licence it is $140^{\circ}$ and $10^{\circ}$ respectively, above and below the horizontal midline. Colour vision, except for protanopia, is not a mandatory 
RESEARCH COMMUNICATIONS

Table 1. Characteristics of vision skills in relation to traffic situations

\begin{tabular}{|c|c|c|c|}
\hline Visual parameters & General characteristics & $\begin{array}{l}\text { Characteristics in relation } \\
\text { to traffic situations }\end{array}$ & Inputs from the literature review \\
\hline Visual acuity & Ability to see small details clearly & Reading distant traffic signs & $\begin{array}{l}\text { Defects in visual acuity results } \\
\text { in doubled crash risk }\end{array}$ \\
\hline Colour vision & Distinguishing different colours & Identification of traffic signals & $\begin{array}{l}\text { Negatively affects driving } \\
\text { performance }\end{array}$ \\
\hline Phoria & $\begin{array}{l}\text { Coordination of both eyes to } \\
\text { correctly identify the } \\
\text { placement of an object ahead }\end{array}$ & $\begin{array}{l}\text { To identify the position of a } \\
\text { vehicle or an obstruction in } \\
\text { front of the driver correctly }\end{array}$ & Affects driving performance \\
\hline Depth perception & $\begin{array}{l}\text { Judgement of distance between } \\
\text { objects }\end{array}$ & $\begin{array}{l}\text { Passing on two-lane road with } \\
\text { oncoming traffic }\end{array}$ & $\begin{array}{l}\text { Defects in depth perception } \\
\text { pose serious problems while } \\
\text { overtaking }\end{array}$ \\
\hline Contrast sensitivity & $\begin{array}{l}\text { Seeing objects in similar } \\
\text { brightness as that of colour }\end{array}$ & $\begin{array}{l}\text { Detecting dark-coloured } \\
\text { pedestrians at night }\end{array}$ & $\begin{array}{l}\text { Poor contrast sensitivity } \\
\text { increases risk of motor vehicle } \\
\text { collision }\end{array}$ \\
\hline Glare recovery & $\begin{array}{l}\text { Ability to resist and recover } \\
\text { from glare }\end{array}$ & $\begin{array}{l}\text { Reduction in visual performance } \\
\text { due to headlight glares }\end{array}$ & $\begin{array}{l}\text { Poor glare recovery } \\
\text { significantly increases reaction } \\
\text { time resulting in accident risk }\end{array}$ \\
\hline Peripheral vision & $\begin{array}{l}\text { Detection of objects at the } \\
\text { sides of the visual fields }\end{array}$ & $\begin{array}{l}\text { Seeing two wheelers } \\
\text { approaching from sides }\end{array}$ & $\begin{array}{l}\text { Defects in visual field increase } \\
\text { reaction time of drivers and } \\
\text { likelihood of night-time crashes }\end{array}$ \\
\hline
\end{tabular}

Source: Traffic Engineering Hand Book, Institute of Transportation Engineers, 1999, 5th edn and previous literature.

requirement in the Australian driver licensing procedure for private vehicles ${ }^{32}$.

India follows a 'single-phase licensing system', which recommends a single phase of driver education and training prior to the written and driving test. Driver education is not mandatory and physical fitness of candidates with respect to visual abilities, hearing, etc. is not evaluated before issuing driver licence. Only the manoeuvring abilities of drivers are considered sufficient for granting the licence ${ }^{33}$.

Among the above-mentioned visual parameters, acuity is the only parameter evaluated as part of the vision test conducted to issue driving licence in India. According to the Motor Vehicle Act 1988 and Central Motor Vehicles Rules 1989, a self-declaration, medical certificate from a registered medical practitioner is sufficient to qualify in the vision test for driver licence, making the law relaxed. Also, the laws are similar for all, irrespective of age and individual characteristics 5 . These lacunae in the present system of driver licensing need immediate attention in order to address road safety issues in India.

The standards followed in other countries may not be directly applicable in aptly assessing driver visual capabilities in India. Therefore, there is an inherent need for extensive research focusing on the area of road safety. Considering these issues, the following objectives have been formulated for the present study to emphasize on the importance of vision functions of drivers influencing road crash involvement in India.
- Evaluating the influence of vision parameters of the drivers on their road crash involvement in India.

- To identify critical driver vision parameters affecting safe driving ability in Indian conditions.

It is evident from the past literature that 'visual functions' are among the crucial physical parameters in relation to safe driving performance. This study attempts to assess the effect of these parameters on crash involvement of Indian drivers.

Three hundred and eighty seven Indian drivers belonging to different organizations, age groups and driving experience volunteered for the study. The sample included drivers from the Karnataka State Road Transport Corporation (KSRTC), which is one of the major public transport undertakings in India established in 1961; Bangalore Metropolitan Transport Corporation (BMTC), which is a Government agency that operates the public transport bus service within Bengaluru, India; Vijayanand Roadlines Limited (VRL), which is one of the leading private business groups in road transportation and logistics in Karnataka, India along with some volunteers from Indian Institute of Science (IISc), Bengaluru, and learner licence applicants and licence renewal aspirants at the Road Transport Office (RTO), Yeshwanthpur, Bengaluru.

The random sample has been categorized based on age to confirm whether there is reasonable representativeness of the population. Table 2 gives details of sample size with respect to age. 
Table 2. Sampling details

\begin{tabular}{|c|c|c|c|c|}
\hline \multirow[b]{2}{*}{ Organization } & \multirow[b]{2}{*}{ Category of vehicle driven/gender } & \multirow[b]{2}{*}{ Age category (years) } & \multicolumn{2}{|l|}{ Sample } \\
\hline & & & Number of drivers & Percentage \\
\hline \multirow[t]{5}{*}{ KSRTC } & Bus drivers/male & $20-30$ & 40 & 25 \\
\hline & & $31-45$ & 80 & 50 \\
\hline & & $46-60$ & 40 & 25 \\
\hline & & Total & 160 & 100 \\
\hline & & $(\mu=38.1 ; \sigma=9.16)$ & & \\
\hline \multirow[t]{5}{*}{ BMTC } & Bus drivers/male & $20-30$ & 4 & 5.13 \\
\hline & & $31-45$ & 47 & 60.26 \\
\hline & & $46-60$ & 27 & 34.62 \\
\hline & & Total & 78 & 100 \\
\hline & & $(\mu=42.82 ; \sigma=8.01)$ & & \\
\hline \multirow[t]{5}{*}{ VRL } & Bus and freight vehicle drivers/male & $20-30$ & 11 & 22 \\
\hline & & $31-45$ & 26 & 52 \\
\hline & & $46-60$ & 13 & 26 \\
\hline & & Total & 50 & 100 \\
\hline & & $(\mu=36.9 ; \sigma=8.64)$ & & \\
\hline \multirow[t]{5}{*}{ IISc } & Private vehicle drivers/male and female & $20-30$ & 27 & 47 \\
\hline & & $31-45$ & 16 & 28 \\
\hline & & $46-60$ & 14 & 25 \\
\hline & & Total & 57 & 100 \\
\hline & & $(\mu=37.14 ; \sigma=12.51)$ & & \\
\hline \multirow[t]{10}{*}{ RTO } & (Learner/driver/renewal licence applicants) & $20-30$ & 25 & 104 \\
\hline & private vehicle drivers/male and female & $31-45$ & 11 & 46 \\
\hline & & $46-60$ & 7 & 29 \\
\hline & & Total & 43 & 100 \\
\hline & & $(\mu=31.81 ; \sigma=11.79)$ & & \\
\hline & Total sample & $20-30$ & 106 & 27 \\
\hline & & $31-45$ & 180 & 47 \\
\hline & & $46-60$ & 101 & 26 \\
\hline & & Total & & \\
\hline & & $(\mu=129 ; \sigma=44.24)$ & 387 & 100 \\
\hline
\end{tabular}

Personal details and road crash histories of tested drivers were obtained from organizational databases. For some samples such as personal vehicle drivers from IISc and RTO, where organizational databases were unavailable, a structured questionnaire was used to collect accident history information from the participants. As drivers participated in the study voluntarily, they were willing to provide data. The data were used to relate the vision test results to the crash involvement tendency of the tested drivers. The collected data included age of the driver, number of years of driving experience and number of crashes he/she has been involved in.

Driver vision skills were tested using 'DVS-GT Deluxe Vision Screener-Model \# 1158WE' instrument. The visual functions tested included visual acuity, colour vision, phoria, night vision, depth perception, contrast sensitivity, glare recovery, peripheral vision and vertical field of vision. Appendix 1 provides the test criteria used to evaluate the drivers.

The tested drivers were categorized as acceptable (1) or unacceptable (2) based on test results. The vision eval- uation standards adopted in this study are followed worldwide by ophthalmologists for general vision testing and also in the licensing system of some countries (for example: Washington, USA) to screen applicants for driver licence.

The data obtained during the study were tabulated and coded for further analysis. Ratio analysis and $z$-test of the sample were conducted. A generalized linear model (GLM) was developed using univariate analysis of variance (ANOVA) and one-way ANOVA with repeated measures. GLME is an extension of classic linear modelling incorporating response variables that follow any probability distribution in the exponential family ${ }^{34}$, initially coined by Nelder and Wedderburn. The explanatory variables in this study (vision test results) were qualitative and of categorical form, whereas the response variables were quantitative (number of crashes). GLM was found to be the most appropriate method for such data types, whose means do not follow normal distribution and instead are multiplicatively related to the explanatory variables ${ }^{35}$. 

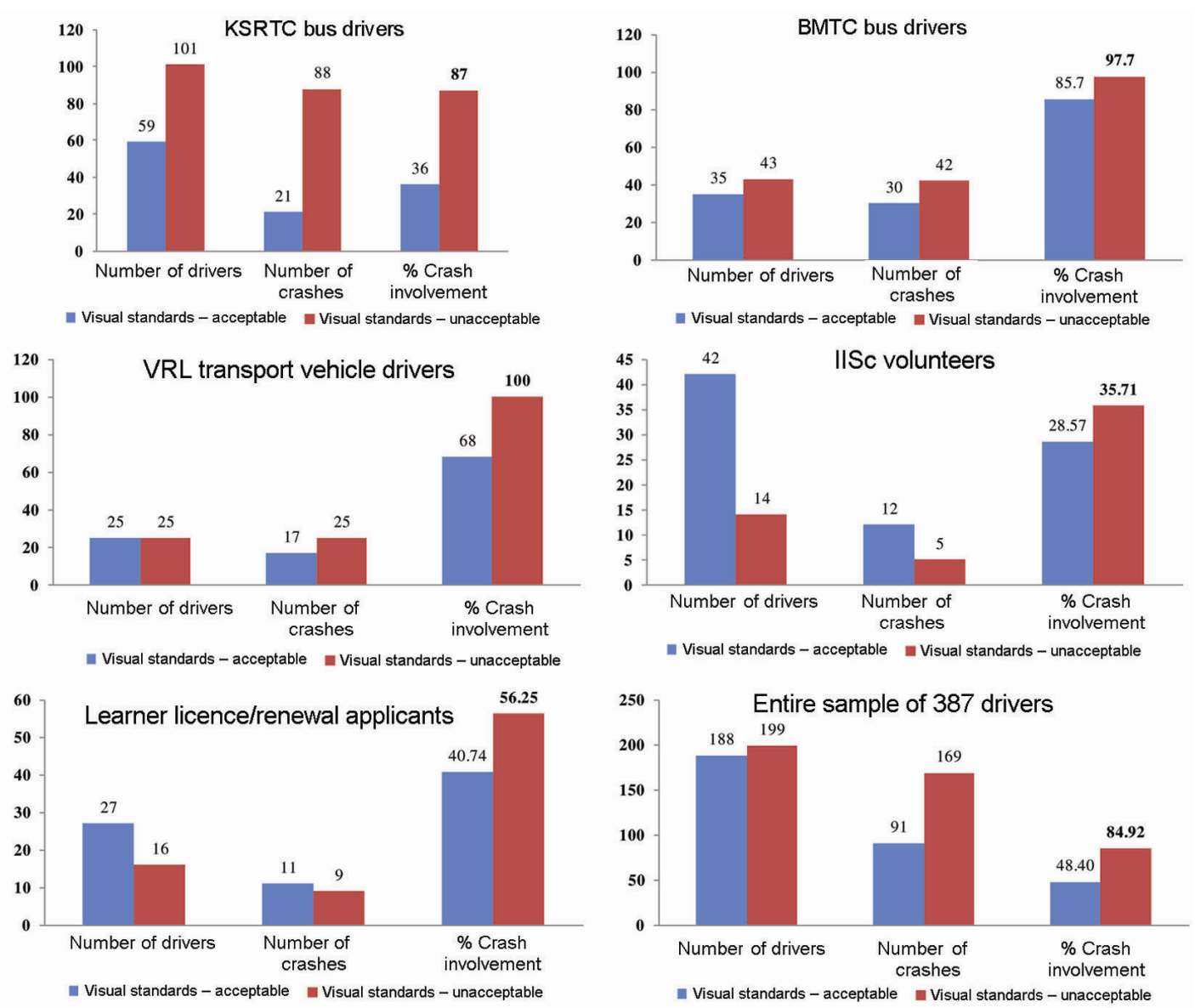

Figure 2. Ratio analysis results.

The vision test results of all the above-mentioned samples have been summarized and the percentage of road crash involvement of the tested drivers with respect to the vision test results has been obtained from ratio analysis (Figure 2).

The vision test results reveal that out of the 160 KSRTC drivers tested, 101 have at least one visual defect, i.e. $63.75 \%$ of the drivers did not satisfy the minimum vision requirements for driving. A simple comparison of the road crash histories of the drivers to the vision test results shows that the crash involvement rates are high (up to $87 \%$ ) in drivers categorized as 'unacceptable'. The number of BMTC drivers involved in road crashes with unacceptable vision standards is high (58.3\%) when compared to those with acceptable visual standards.

Among 50 drivers tested from VRL, 50\% qualified the required standards, whereas the other $50 \%$ failed in at least one of the tested vision parameters. Fifty-six volunteers (both male and female) from IISc, including professors, research students and administrative staff were tested for vision. It is important to note that the crash histories of these tested subjects were obtained from selfreports. The vision test results and the road crash details showed that the drivers with visual defects were involved in a relatively higher number of road crashes compared to those with normal vision. Forty-three learning licence/ driver licence/licence renewal applicants from the RTO at Yeshwanthpur, were also tested as a part of the study. Twenty-seven of them qualified with acceptable visual standards, while 16 did not. Significant number of road crashes of novice drivers was observed in this sample group, although they do not have a permit to ride. Leniency of the present licensing system and traffic law enforcement methods in India are depicted in these cases.

Table 3 shows the cumulative test results of the entire sample of 387 drivers. More than half of the entire sample $(52 \%)$ failed in at least one of the vision parameters tested. The percentage of crash involvement of subjects with at least one visual disability was significantly higher $(81 \%)$ than those without visual disability.

Two-tailed $z$-test was also conducted to verify whether there is significant difference between the crash rates of drivers with visual defects and those with normal vision. Table 4 presents the $z$-test results of the entire sample based on the following hypothesis: (i) null hypothesis, $H_{0}: \mu_{0}=\mu_{1}$ and (ii) alternate hypothesis, $H_{1}: \mu_{0} \neq \mu_{1}$, where $\mu_{0}$ is the mean of the sample of number of accidents by drivers with visual defects, and $\mu_{1}$ is the mean of 
Table 3. Aggregate vision test results

\begin{tabular}{|c|c|c|c|c|c|c|}
\hline \multirow[b]{2}{*}{ Vision parameters } & \multicolumn{2}{|c|}{ Vision test results } & \multicolumn{2}{|c|}{ Crashes involved } & \multicolumn{2}{|c|}{ Percentage of crash involvement } \\
\hline & Unacceptable & Acceptable & Unacceptable & Acceptable & Unacceptable & Acceptable \\
\hline Left eye acuity & $45(12 \%)$ & $342(88 \%)$ & 44 & 217 & 98 & 63 \\
\hline Right eye acuity & $60(16 \%)$ & $327(84 \%)$ & 62 & 199 & 103 & 61 \\
\hline Night vision & $39(10 \%)$ & $348(90 \%)$ & 36 & 225 & 92 & 65 \\
\hline Acuity (both eyes) & $38(10 \%)$ & $349(90 \%)$ & 36 & 225 & 95 & 64 \\
\hline Phoria & $6(2 \%)$ & $381(98 \%)$ & 2 & 259 & 33 & 68 \\
\hline Contrast sensitivity & $17(4 \%)$ & $370(96 \%)$ & 18 & 243 & 106 & 66 \\
\hline Glare recovery & $25(6 \%)$ & $362(94 \%)$ & 23 & 238 & 92 & 66 \\
\hline Depth perception & $111(29 \%)$ & $276(71 \%)$ & 106 & 155 & 95 & 56 \\
\hline Peripheral vision & $6(2 \%)$ & $381(98 \%)$ & 6 & 255 & 100 & 67 \\
\hline Vertical field of vision & $85(22 \%)$ & $302(78 \%)$ & 77 & 184 & 91 & 61 \\
\hline $\begin{array}{l}\text { Drivers with unacceptable } \\
\text { standard in at least one } \\
\text { of the tested parameters }\end{array}$ & $201(52 \%)$ & $186(48 \%)$ & 162 & 99 & 81 & 53 \\
\hline
\end{tabular}

Table 4. $z$-test results

\begin{tabular}{lcc}
\hline Parameters & $\begin{array}{c}\text { Accidents by drivers } \\
\text { with visual defects }\end{array}$ & $\begin{array}{c}\text { Accidents by drivers } \\
\text { without visual defects }\end{array}$ \\
\hline Mean & 0.803191489 & 0.587939698 \\
Variance & 1.132182273 & 1.112177047 \\
Observations & 188 & 199 \\
Hypothesized mean & 0 & \\
$\quad$ difference & & \\
$z$ & 1.997609288 & \\
$P(Z \leq z)$ one-tail & 0.022879518 & \\
$Z$ critical one-tail & 1.644853627 & \\
$P(Z \leq z)$ two-tail & 0.045759036 & \\
$Z$ critical two-tail & 1.959963985 & \\
\hline
\end{tabular}

Table 5. Descriptive statistics

\begin{tabular}{lccc}
\hline Vision defect & Mean & Standard deviation & $N$ \\
\hline $\begin{array}{l}\text { 1- Sample with at least one } \\
\quad \text { vision defect }\end{array}$ & 0.59 & 1.055 & 199 \\
$\begin{array}{l}\text { - Sample with no vision defect } \\
\text { Total }\end{array}$ & 0.80 & 1.064 & 188 \\
& 0.69 & 1.063 & 387 \\
\hline
\end{tabular}

the sample of number of accidents by drivers without any vision defects (normal vision).

Here, $z$-statistics is greater than the $z$ critical in the two-tail $z$-test. This implies that the obtained $z$-statistics lies in the rejection area of the normal distribution of the sample. Hence, the null hypothesis $H_{0}$ can be rejected, which leads to the acceptance of the alternate hypothesis $H_{1}$. The result of the analysis is that the means of the samples of the number of accidents of drivers with and without vision defects are different. This indicates that there is significant influence of vision defects over crash association of tested drivers.

GLM was also done to verify whether there is significant difference between the crash rates of drivers with visual defects and those with normal vision. Tables 5 and 6 provide the results.

The results show there is significant influence ( $\sigma$ values $<0.05$.) of vision defects on crash involvement of tested drivers. Also, using GLM, the influence of particular visual defects on the crash rate of drivers has been analysed. Tables 7 and 8 present GLM results.

Here, dependent variable is the number of accidents and the independent variables (fixed factors) are the visual defects - acuity, binocular, colour blindness, phoria, depth perception, contrast sensitivity, glare recovery, peripheral vision, nasal vision and vertical vision. The effect of the fixed factors (visual defects) on the dependent variable (number of accidents) is observed using GLM one way ANOVA with repeated measures on the data.

A repeated measures ANOVA with a greenhouseGeisser correction revealed that mean number of accidents differed statistically significantly between vision defect points $(F(6.276,2422.50)=36.602, P<0.0005)$. Post hoc tests using Bonferroni correction revealed that individual vision defects have influence over the number of accidents. The decreasing order of the influence being phoria, peripheral vision, contrast sensitivity, binocular vision, glare recovery, acuity, vertical vision, colour blindness, nasal vision and depth perception.

The primary goal of the present study was to identify and assess the effect of visual disabilities of drivers on their crash involvement. In the present study, the following uncertainties were observed in the collected data: (a) The crash histories of private vehicle drivers (from IISc and RTO) were collected through self-reports. The data are based on the assumption of their truthfulness. (b) The maximum number of crashes of the tested drivers from KSRTC, BMTC and VRL does not exceed five. This is due to the fact that drivers with more than five crashes are usually dismissed from these organizations. Also, the 
RESEARCH COMMUNICATIONS

Table 6. Test of between-subject effects

\begin{tabular}{lccrrrr}
\hline Source & Type III sum of squares & $\mathrm{d} f$ & Mean square & $F$ & $\sigma$ & Partial eta squared \\
\hline Corrected model & $4.479^{\mathrm{a}}$ & 1 & 4.479 & 3.992 & 0.046 & 0.010 \\
Intercept & 187.084 & 1 & 187.084 & 166.757 & 0.000 & 0.302 \\
Vision defect & 4.479 & 1 & 4.479 & 3.992 & 0.046 & 0.010 \\
Error & 431.929 & 385 & 1.122 & & & \\
Total & 622.000 & 387 & & & \\
Corrected total & 436.408 & 386 & & & & \\
\hline
\end{tabular}

${ }^{\mathrm{a}} R$ squared $=0.010$ (adjusted $R$ squared $\left.=0.008\right)$.

Table 7. Descriptive statistics

\begin{tabular}{lccc}
\hline Parameters & Mean & Standard deviation & $N$ \\
\hline Left eye acuity & 1.94 & 0.237 & 387 \\
Right eye acuity & 1.95 & 0.216 & 387 \\
Binocular night mode & 1.97 & 0.180 & 387 \\
Binocular day mode & 1.96 & 0.199 & 387 \\
Colour test & 1.92 & 0.276 & 387 \\
Phoria & 1.99 & 0.101 & 387 \\
Depth perception & 1.75 & 0.435 & 387 \\
Contrast sensitivity & 1.97 & 0.166 & 387 \\
Glare recovery & 1.95 & 0.222 & 387 \\
Peripheral vision & 1.98 & 0.124 & 387 \\
Nasal vision & 1.79 & 0.407 & 387 \\
Vertical upward vision & 1.93 & 0.255 & 387 \\
Vertical downward vision & 1.94 & 0.241 & 387 \\
\hline
\end{tabular}

complete crash histories of the tested subjects (before joining the organization) were not available.

The results show a significant relation between roadcrash tendencies of drivers and visual defects such as phoria, peripheral vision and contrast sensitivity.

It is important to note in the present study that drivers with no visual defects were also involved in crashes. In these cases, the causal factors other than vision such as environment, road condition, psychological condition of the driver, etc. may have been the significant underlying cause for the road crashes.

Another interesting aspect observed from the study is that many of the licensed drivers tested did not qualify the minimal vision standards. A similar study conducted at Guwahati, Assam also identified several shortcomings in the visual capabilities of licensed drivers ${ }^{5}$. It was observed that out of the 189 licensed drivers tested for vision, $3 \%$ failed in phoria, $12 \%$ in the depth judgement, $7 \%$ in glare recovery, $5 \%$ in nasal vision, $15 \%$ in acuity, $5 \%$ in night vision, and $5 \%$ in colour vision. These results depict the flexibility in the current licensing practices, which may ultimately reduce driving safety. The test results emphasize the need for stringent scrutiny, particularly of the commercial vehicle drivers prior to their licensing and employment.

In practice, visual acuity, visual field and colour vision are the mandatory vision requirements in many of the International driver licensing systems, including Canada,
Germany, USA and Australia. Table 9 shows a comparison between some of the vision requirements, nationally (with respect to India) and internationally.

Apart from the aforementioned parameters the influence of phoria, contrast sensitivity, depth perception, etc. has been closely scrutinized in this study and is realized to have critical influence on road safety.

From the present study it is empathized that vision tests are to be made an integral part of the recruitment process of drivers, especially for commercial and public services. In order to address this issue of road safety in the present scenario, vision skill evaluation and vision rectification programmes need to be conducted for the drivers already employed as a part of safe driving performance enhancement programmes. Awareness sessions should also be considered as a vital step towards providing a platform for the drivers for self-realization and assessment of their visual limitations and further assistance in seeking medical aid in resolving the problem. Along with these measures, planned scheduling of drivers with night vision and glare recovery problems to prevent them from night-time driving can be taken up to improve safety of passengers and other road users.

Road safety is a critical issue that needs focus in this era of increased road-crash deaths. India is one of the perilous countries in terms of road fatalities in the world. The motivation behind this study was to scientifically analyse the effect of vision functions on road crashes. Different visual functions and their influence on roadcrash involvement were reviewed by assessing them with the help of 'DVS-GT deluxe vision screener' instrument. A total of 387 drivers from various organizations volunteered for the study. Road-crash histories of the subjects were also collected. The results were analysed using statistical tools.

This study helps in understanding the importance of visual requirements for safe driving. It highlights the importance of addressing the road safety issue collectively using 3Es: education, engineering and enforcement with respect to driver vision as well. The method adopted in the study proves to be useful in screening candidates during the issue of driver licences.

Vision parameters other than the general acuity such as peripheral vision, contrast sensitivity, glare recovery, etc. have been found to effect safety performance of drivers. 
RESEARCH COMMUNICATIONS

Table 8. Tests of between-subjects effects

\begin{tabular}{lcccccc}
\hline Source & Type III sum of squares & $\mathrm{d} f$ & Mean square & $F$ & $\sigma$ & Partial eta sqaured \\
\hline Intercept & 18655.803 & 1 & 18655.803 & 121804.954 & 0.000 & 0.997 \\
Error & 59.120 & 386 & 0.153 & & & \\
\hline
\end{tabular}

Table 9. Vision requirement standards for safe driving

\begin{tabular}{|c|c|c|c|}
\hline Vision parameters & Specifications & International standards & Indian standards \\
\hline \multirow[t]{3}{*}{ Visual acuity } & $6 / 12(0.5)$ or better & $\begin{array}{l}\text { No visual acuity-based objection. Provision of unrestricted driving } \\
\text { licence even if acuity could be further improved by glasses or lenses }\end{array}$ & $6 / 18$ or better \\
\hline & $\begin{array}{l}<6 / 12(<0.5) \text { to } \\
6 / 60(0.1)\end{array}$ & $\begin{array}{l}\text { Individual consideration, which may result in restriction or denial. } \\
\text { Evaluation should include visual and non-visual factors and a road } \\
\text { test when in doubt. Some licences may be granted }\end{array}$ & \\
\hline & $<6 / 60(<0.1)$ & No driving licence & \\
\hline \multirow[t]{2}{*}{ Field of vision } & $\begin{array}{l}120^{\circ} \text { horizontal, } \\
40^{\circ} \text { vertical or better }\end{array}$ & $\begin{array}{l}\text { No visual field-based objection. Provision of unrestricted driving } \\
\text { licence, provided that the field is about evenly divided around fixation } \\
\text { and that no attention-related problems are identified }\end{array}$ & $\begin{array}{l}\text { Not } \\
\text { considered }\end{array}$ \\
\hline & Worse & $\begin{array}{l}\text { Individual consideration, which may result in restriction or denial. } \\
\text { Evaluation should include visual and non-visual factors and a road } \\
\text { test when in doubt. Some licences maybe granted, some may not }\end{array}$ & \\
\hline Colour test & $\begin{array}{l}\text { To identify the } \\
\text { difference between } \\
\text { red and green }\end{array}$ & Required to pass colour test & Not considered \\
\hline
\end{tabular}

Source: Vision requirements for driving safety - International Council of Ophthalmology, 2005.

Appendix 1. Criteria used to categorize vision screening results

\begin{tabular}{|c|c|c|c|}
\hline Type of test & Test procedure & Acceptable & Unacceptable \\
\hline $\begin{array}{l}\text { Visual acuity - right eye, } \\
\text { left eye, and for both } \\
\text { eyes (night and day mode) }\end{array}$ & $\begin{array}{l}\text { The subject is made to identify numbers of varying sizes } \\
\text { that appear on the screen. }\end{array}$ & $\begin{array}{l}\text { Vision range between } \\
6 / 6 \text { and } 6 / 12 \text {. }\end{array}$ & $\begin{array}{l}\text { Vision range more } \\
\text { than } 6 / 12 \text {. }\end{array}$ \\
\hline $\begin{array}{l}\text { Colour test (green, red and } \\
\text { yellow) }\end{array}$ & $\begin{array}{l}\text { The subject is asked to identify the colours he/she is } \\
\text { able to see on the screen. }\end{array}$ & $\begin{array}{l}\text { If subject identifies all } \\
\text { three colours. }\end{array}$ & $\begin{array}{l}\text { If the subject does not } \\
\text { identify colours correctly. }\end{array}$ \\
\hline Phoria/Binocular vision & $\begin{array}{l}\text { The subject is made to identify the placement of a red } \\
\text { dot that is visible on the screen. }\end{array}$ & Dot within rectangle. & Dot outside the rectangle. \\
\hline $\begin{array}{l}\text { Depth perception (subject is } \\
\text { asked to identify six traffic } \\
\text { signs and asked which is } \\
\text { farther and which is nearer) }\end{array}$ & $\begin{array}{l}\text { The subject is asked to identify some of the road sign } \\
\text { targets placed at different positions and is also asked to } \\
\text { distinguish the targets that appear relatively closer } \\
\text { or farther. }\end{array}$ & $\begin{array}{l}\text { If both near and far signs } \\
\text { are observed correctly. }\end{array}$ & $\begin{array}{l}\text { If the subject fails to } \\
\text { identify the position of } \\
\text { close and far away signs. }\end{array}$ \\
\hline Contrast sensitivity & $\begin{array}{l}\text { In night mode, the subject is presented with numbers } \\
\text { in three columns with an acuity of } 6 / 21 \text {, } \\
\text { each column set at different contrast. }\end{array}$ & $\begin{array}{l}\text { If subject is able to read } \\
\text { within } 40 \% \text { contrast. }\end{array}$ & $\begin{array}{l}\text { If the subject is unable to } \\
\text { read within } 40 \% \text { contrast. }\end{array}$ \\
\hline Glare recovery & $\begin{array}{l}\text { In night mode, the subject is exposed to illuminated } \\
\text { flash of light for a period of } 3 \mathrm{sec} \text {, and asked to } \\
\text { read numbers on screen within } 5 \mathrm{sec} \text {. }\end{array}$ & $\begin{array}{l}\text { If the subject identifies at } \\
\text { least six out of seven } \\
\text { numbers in any one line. }\end{array}$ & $\begin{array}{l}\text { If the subject fails to } \\
\text { read at least six out of the } \\
\text { given numbers in any line. }\end{array}$ \\
\hline Horizontal field vision test & $\begin{array}{l}\text { The subject is asked to identify LED targets kept at } \\
55^{\circ}, 70^{\circ} \text { and } 85^{\circ} \text { angles. This test is conducted for } \\
\text { each eye separately. }\end{array}$ & $\begin{array}{l}\text { If the subject identifies } \\
\text { the LED targets } \\
\text { @ } 70^{\circ} \text { or } 85^{\circ} \text {. }\end{array}$ & $\begin{array}{l}\text { If the subject fails to } \\
\text { identify all targets } \\
\text { at } 70^{\circ} \text { or } 85^{\circ} \text {. }\end{array}$ \\
\hline $\begin{array}{l}\text { Vertical field vision test - } \\
\text { both upper and lower }\end{array}$ & $\begin{array}{l}\text { The subject is asked to identify LED targets kept at } \\
35^{\circ} \text { angle in the vertical plane. This test is conducted } \\
\text { for each eye separately. }\end{array}$ & $\begin{array}{l}\text { If the subject identifies } \\
\text { the target. }\end{array}$ & $\begin{array}{l}\text { If the subject fails to } \\
\text { identify the target. }\end{array}$ \\
\hline
\end{tabular}

Source: Keystone DVS-GT Deluxe Record Form for use with Model 1158.

*Note: $6 / 6$ vision refers to normal vision indicated by the ability to accurately read the vision test chart placed at a distance of $6 \mathrm{~m}$ from the eye. $6 / 12$ vision refers to the ability to accurately read the vision test chart placed at a distance of $6 \mathrm{~m}$, which a normal vision person can read from a distance of $12 \mathrm{~m}$. 


\section{RESEARCH COMMUNICATIONS}

These tests are required to be made mandatory for commercial and public service vehicle drivers to begin with. There is a huge need to amend the Indian standards of vision testing for drivers. The governing laws in India with respect to driver licensing procedures need to be appropriately amended to create safe drivers by strict visual screening before issuing driving licence. Persons with unacceptable standards of visual functions must either be issued a regulated driving licence or licence must be issued only after the problem is medically rectified, if possible.

The present road accident investigation practices followed in India do not include a systematic methodology to test the visual defects in the driver at the time of accident. Therefore, scientific and accurate data to correlate the vision defect of drivers to their crash involvement are unavailable. However, this can form a scope in future studies wherein road accident investigations are conducted with assessment of visual functions of the driver, based on which a detailed study can be conducted. An enhanced and representative sample size of drivers from all vehicle categories and driving experiences is required to obtain results that are more representative. Also, other physical parameters such as auditory skills, limb strength, reaction time, etc. and psychological parameters such as sensation seeking, driver fatigue, aggression, etc. play an important role in safe driving activity. Therefore, a thorough study is necessary to clearly understand the effect of overall human factors on safe driving. A realtime evaluation of these psychophysical parameters would allow a better appreciation of their influence on driving. Experimental studies using EEG signals, heart rate variation, etc. may be adopted in this direction.

Another important aspect that requires consideration is the calibration of the test methodology adopted in the present study. This is essential to assess its adaptability for testing in Indian conditions to provide a better insight regarding the influence of visual skills on Indian road safety. Further, calibration of the test methodology becomes necessary for incorporation in practical issues such as traffic engineering, policy-making, education and enforcement.

1. Hu, P. S. and Reuscher, T. R., Summary of travel trends: 2001 national household travel survey. Transportation Research Board, USA, 2004

2. Road accident in India, Ministry of Road Transport and Highways, Government of India, 2013.

3. Elslande, V. P. and Fouquet, K., Analyzing human functional failures in road accidents, TRACE, Final report, 2007.

4. Evans, L., Traffic Safety, Science Serving Society, Michigan, 1991.

5. Chauhan, S. and Verma, A., Assessing the impact of driver attributes on road safety and mobility. In XVI Pan American Conference on Traffic and Transport (PANAM-2010), Lisbon, Portugal, 2010.

6. Dewar, R. E., Olson, P. L. and Alexander, G. J., Human Factors in Traffic Safety, Lawyers \& Judges Publishing Company, Tuscon, Arizona, 2007, 2nd edn.
7. Anstey, K. J., Wood, J., Lord, S. and Walker, G. J., Cognitive, sensory and physical factors enabling safety in older adults. Clin. Psychol. Rev., 2005, 25, 45-65.

8. Singh, H. and Dhattarwal, S. K., Pattern and distribution of injuries in fatal road traffic accidents in Rohtak. J. Indian Acad. Forensic Med., 2004, 26(1), 20-23.

9. Kaul, A., Sinha, U. S., Pathak, Y. K., Singh, A., Kapoor, A. K., Sharma, S. and Singh, S., Fatal road traffic accidents, study of distriibution, nature and type of injury. J. Indian Acad. Forensic Med., 2005, 27(2), 71-76.

10. Wood, J. M., Horswill, M. S., Lacherez, P. F. and Anstey, K. J., Evaluation of screening tests for predicting older driver performance and safety assessed by an on-road test. Accid. Anal. Prevent., 2013, 50, 1161-1168.

11. Matas, N. A., Nettelbeck, T. and Burns, N. R., Cognitive and visual predictors of UFOV performance in older adults. Accid. Anal. Prevent., 2014, 70, 74-83.

12. Friedman, C., McGwin, G. J., Ball, K. and Owsley, C., Association between higher order visual processing abilities and a history of motor vehicle collision involvement by drivers aged 70 and over. Invest. Ophthalmol. Vis. Sci., 2013, 54(1), 778-782.

13. Hofstetter, H. W., Visual acuity and highway accidents. J. Am. Optom. Assoc., 1976, 47(7), 887-893.

14. Maag, U., Vanasse, C., Dionne, G. and Laberge-Nadeau, C., Taxi drivers accidents: how binocular vision problems are related to their rate and severity in terms of the number of victims. Acid. Anal. Prevent., 1997, 29(2), 217-224.

15. Poulter, D. R. and Wann, J. P., Errors in motion processing amongst older drivers may increase accident risk. Accid. Anal. Prevent., 2013, 57, 150-156.

16. Desapriya, E., Harjee, R., Brubacher, J., Hewapathirane, C. H. D. S., Subzwari, S. and Pike, I., Vision screening of older drivers for preventing road traffic injuries and fatalities (review). Cohcrane Database of Systematic Reviews, Canada, 2014.

17. Javitt, J. C., Risk of motor vehicle crashes in patients with cataract surgery. JAMA, 2002, 288(18), 2262.

18. Cole, B. L., Protan colour vision deficiency and road accidents. Clin. Exp. Optom., 2002, 85(4), 246-253.

19. Padmanaban, J., Rajaraman, R., Narayan, S., Ramesh, B. and Stadter, G., Analysis of in-depth crash data on Indian national highways and impact of road design on crashes and injury severity. In 4th International ESAR Conference, Hanover, Germany, 2010.

20. Nighttime glare and driving performances, National Highway Traffic Safety Administration, USA, 2007.

21. Tang, Y. B., The effects of age and glare on driving, Doctoral dissertation, The Hong Kong Polytechnic University, 2012.

22. Sandlin, D., McGwin Jr, G. and Owsley, C., Association between vision impairment and driving exposure in older adults aged 70 years and over: a population based examination. Acta Ophthalmol., 2014, 92(3), 207-212.

23. Snowden, R. J., Stimson, N. and Ruddle, R. A., Speed perception fogs up as visibility drops. Nature, 1998, 392, 450.

24. Stone, L. S. and Thompson, P., Human speed perception is contrast dependent. Vis. Res., 1992, 32, 1535-1549.

25. Thompson, P., Brooks, K. and Hammett, S. T., Speed can go up as well as down at low contrast: implications for models of motion perception. Vis. Res., 2006, 46, 782-786.

26. Burg, A., Horizontal phoria as related to age and sex. Transp. Res. Board, 1968, 45(6), 345-350.

27. Lamble, D., Summala, H. and Hyvärinen, L., Driving performance of drivers with impaired central visual field acuity. Accid. Anal. Prevent., 2002, 34(5), 711-716.

28. Szlyk, J. P., Fishman, G. A., Severing, K., Alexander, K. R. and Viana, M., Evaluation of driving performance in patients with juvenile macular dystrophies. Arch. Ophthalmol., 1993, 111(2), $207-212$. 
29. Johnson, C. A. and Keltner, J. L., Incidence of visual field loss in 20,000 eyes and its relationship to driving performance. Arch. Ophthal., 1983, 101(3), 371-375.

30. Steinkuller, P. G., Legal vision requirements for drivers in the United States. Am. Med. Assoc. J. Ethics, 2010, 12(12), 938-940.

31. Government of UK (n.d.), Retrieved from https://www.gov.uk/ driving-eyesight-rules

32. Optometry Victoria Strategic Plan 2015-18 (n.d.). Optometry Australia, Retrieved from www.optometry.org.au; http://www. optometrists.asn.au/vic/practiceinfo/driving-vision-standards.aspx

33. Verma, A., Velmurugan, S. and Chakrabarty, N., Recommendations for driver licensing and traffic law enforcement aiming to improve road safety. Curr. Sci., 2011, 100(9), 1373-1385.

34. Kim, S. H., Chung, S. B. and Song, K. S., Development of an accident prediction model using GLM (generalized log-linear model) and EB method: a case of Seoul. J. East. Asia Soc. Transp. Stud., 2005, 6, 36669-36682.

35. Nelder, J. A. and Baker, R. J., Generalized linear models. Encycl. Stat. Sci., 1972, 135(3), 370.

ACKNOWLEDGEMENTS. We thank the Council of Scientific and Industrial Research, New Delhi for funds (Project No. 70(0067)/ 11/EMR-II). We also thank KSRTC, BMTC, VRL, IISc, Bengaluru and RTO (Yeshwanthpur, Bengaluru) for providing sample drivers for the study and also the required accident histories of the tested drivers. Also, we would like to thank M-Tech students Ms N. S. L. Aparna from NIT Trichy, and Mr S. Rohit from Reva Institute of Technology and Management, Bengaluru for data compilation and assistance in the analyses.

Received 5 December 2014; revised accepted 27 October 2015

\section{Study of traffic noise in urban street canyons of Bengaluru city}

\author{
Halesh Koti $^{1{ }^{1 *}}$, G. Ranganath $^{1}$ and \\ H. N. Rajakumara ${ }^{2}$ \\ ${ }^{1}$ Mechanical Engineering Department, \\ Adhiyamaan College of Engineering, Hosur 635 109, India \\ ${ }^{2}$ Civil Engineering Department, R.R. Institute of Technology, \\ Chikkabanavara, Bengaluru 560 090, India
}

In urban street canyons, external noise environment is a critical restriction to the opening of building windows for natural ventilation. The high external noise intensities are often used to substantiate the utilization of air conditioning systems in residential and commercial buildings. Therefore, a systematic method of examining the noise levels in urban street canyons is essential if the potential for natural ventilation is to be estimated. The noise levels and natural ventilation in urban street canyons depend on many aspects such as

*For correspondence. (e-mail: halkoti@gmail.com) existing street dimensions, height of buildings and traffic density. A study has been carried out in a street to examine the variation in noise levels vertically in order to provide technical inputs on natural ventilation potential in urban street canyons. In this study, a number of noise measurements were made in urban street canyons of Bengaluru City, in residential and commercial areas with respect to aspect ratio (height of building/street width) changing from 1.0 to 4.0 . With the help of measured data, a statistical model was developed. A linear regression analysis has been used. The model can be used to predict variation of noise level in vertical direction in urban street canyons. The variation of noise level is found to be a function of street width and height of a building above the street level, but the highest level of reduction is almost entirely a function of the aspect ratio. The rate of attenuation of foreground noise $\left(L_{10}\right)$ is greater than the background noise $\left(L_{90}\right)$ with height.

Keywords: Aspect ratio, noise attenuation, traffic noise, urban street canyon.

CANYON-like streets in urban areas vary considerably in width and in the height of the buildings which border them $^{1}$. The facades of some of the buildings are plain and some have balconies. A majority of buildings in residential streets as well as some of the office buildings in commercial streets have balconies. The facades at ground level can be even more complex. The ground floor is generally set back with colonnades.

Some noise measurements were taken in street canyons of Bengaluru city. The measurements were made to assess the effect of noise level in the vertical direction above street level. This study aims to provide guidance about the effect on the external noise environment of the street width, aspect ratio and the height of the location above street level. This requires assessment of the relative significance of the direct sound and the reverberant noise level in the street canyon. Other important factors to be considered are the traffic density and noise associated with it in the street. The ratio of the height of the buildings in street canyons $(H)$ to the width of the street $(w)$ is known as the 'aspect ratio' (AR) of the street with assumption that the buildings on either side are at same height. However in reality, this may not be the case. In this study, the average height of the buildings in street canyons has been taken to get $\mathrm{AR}=\left(H_{1}+H_{2}\right) / 2 \mathrm{w}$ (Figure 1). The facade of building also varies considerably with and without balconies.

Noise measurements were made in Bengaluru at nine selected street canyons comprising residential zone, commercial zone, silent zone and heavy traffic zone (Table 1). In each street, canyon measurements were taken outside the windows of buildings. The aim of these noise measurements was to assess the vertical variation of noise level with respect to measurement location above 